\title{
OPEN SCHOOLING: APPLICATION IN THE STUDY OF THE FOREST
}

\author{
L. Mulero, I. Torra, M.D. Grau \\ Exploratori-Universitat Politècnica de Catalunya (SPAIN)
}

\begin{abstract}
In this work, it has been doing a comparison between some really knowing methodologies of studentcentred learning -Learning by doing; method Montessori; Constructivism; Constructionism and the innovating system Open Schooling. The objective is being able to evaluate it.

Specifically, it has been working with an European project: Project Erasmus+ Open Science Schooling: Fostering re-engagement in science learning through open science schooling. The most important goal of the project consists in encouraging "Open Science Schooling" where schools, in cooperation with other stakeholders, become an agent of community well-being; families are encouraged to become real partners in school life and activities; professionals from enterprise, civil and wider society are actively involved in bringing real-life projects into the classroom. The project is composed of three periods and nine phases, furthermore a conclusive phase. The blue period, the first one, aims to create consensus and readiness among partners, teachers and students and to mobilise the resources to collaborate with the project, locally and transnationally. The Green Period, the second one, will create the knowledge, experience and documentation on which the project outcomes will be based; the resource creation will follow the project's five didactic challenges, stepwise building up capacity and resources towards the Red Period: the production and sharing of final results. The project's final period, the Red Period, will transform the produced raw material, including from the Open Science Schooling Encounter, into high-quality useful outcomes. The outcome presentation will build on the project's attractive access design that was developed along the project. The final production will, of course, be accompanied by systematic and powerful local and European level sharing and dissemination.
\end{abstract}

The study case is a school located in Gironella, Berguedà. During the first twelve months, the last school year, it was studied the environment with the mean idea of saving energy. The students have visited several companies and enterprises, in order to known their local community. The implication of the students' families was essential for a good structure of the project. At the fifth phase, in this school year, it was selected the topic to study: "The forest: exploitation and contribution to the sustainability". It has been chosen, given that the region contributes $70 \%$ of the wood of Catalonia. It is considered to be a topic that involves different stakeholders of local society: Wood sector companies (sawmills, biomass plant ...), the food sector (mushrooms, aromatic plants, honey ...), Research centres (Forest Technology Centre of Catalonia, Universitat Politècnica de Catalunya, Fundació Alicia ...), Administration (Department of Education, City Councils, Regional Council ...) ... the central theme of the Forest will be approached from two points of very differentiated view: Use as raw material on the one hand, and contribution from the forest to the sustainability of the other.

Keywords: Open Science Schooling, student-centred learning methodologies, forest, save energy.

\section{INTRODUCTION}

We live in a highly technician society. People need more knowledge and skills to solve problems in an increasingly complex world. In this context it is essential that children, teenagers and young people develop the necessary tools to critically analyse information and make decisions, address the challenges of the industry, technological innovation and society. Taking into account the growing need for people trained in science and engineering for future professions until 2025, it is key to develop strategies that encourage the motivation of young people for this kind of studies. Increasingly, learning can be carried out in three environments: formal, non-formal and informal, in which different areas of society collaborate beyond the elements of the world of education. Open Schooling aims to include all these levels of education in the teaching of science and technology, involving different sectors of the local community in order to bring science education closer to all citizens: families, companies, 
associations, politicians, administrations ... The activities are also programmed in the most transversal way possible by applying the STEAM (Science, Technology, Engineering, Art and Mathematics) methodology.

The OSS pretends that the educational centres, in cooperation with other sectors of the society, become an agent to promote the welfare of the community. Families are part of the project as a member, companies and other sectors of society have to actively engage in solving real life problems in the classroom.

In Catalonia, the Secondary School, as a result of the observation of the characteristics of the region (Berguedà), has chosen as a key issue for its community to work around the natural resources of the forest. The design of the program will be based on the Sustainable Development Goals (SDG) of Agenda 2030. It will be studied how each SDG links with the activities that are carried out and with the description of the uses of the forest of the Food and Agriculture Organization (FAO). Through different questionnaires, the activities related to the forest and the relationship with the different sectors of society (stakeholders) will be monitored. Based on these stakeholders that will be related to the students, and based on the SDG, it is intended that from a scientific-technical point of view there appear questions in several fields, even of a social nature. This fact must allow the relationship between the scientific-technical knowledge and the real problems.

\section{METHODOLOGY}

This work is linked to an European project: Project Erasmus+ Open Science Schooling: Fostering reengagement in science learning through Open Science Schooling (OSS). The project is composed of three periods and nine phases, furthermore a conclusive phase, as shown in the Table 1.

Table 1: Phases of OSS Project

\begin{tabular}{llr}
\hline \hline \multicolumn{3}{c}{ BLUE PERIOD (4 months) } \\
\hline PHASE 1 & Consensus & Sep-Oct 2017 \\
\hline PHASE 2 & Mobilization & Nov-Dec 2017 \\
\hline \multicolumn{3}{c}{ GREEN PERIOD (20 months) } \\
\hline PHASE 3 & Understanding & Jan-Feb 2018 \\
\hline PHASE 4 & Integration & Mar-Apr 2018 \\
\hline PHASE 5 & Open practice $2018-$ Apr \\
& EhasE 6 & Evaluation and documentation \\
\hline PHASE 7 & Eco-systems & May-Jun 2019 \\
\hline \multicolumn{3}{c}{ RED PERIOD (6 months) } \\
\hline PHASE 8 & Access design & Jul-Sep 2019 \\
\hline PHASE 9 & Production and sharing & Sep-Oct 2019 \\
\hline \hline
\end{tabular}

\section{BLUE PERIOD}

The blue period aims to create consensus and readiness among partners, teachers and students and to mobilise the resources to collaborate with the project, locally and transnationally

PHASE 1: Consensus has been created through the project's partner Guide Package, made available at least 2 weeks before the kick-off meeting, and through the open dialogues at the kick-off meeting. The consensus process includes the participation of the project's student teams.

PHASE 2 It has been mobilizing schools and community collaborators to interact with the project along its Green Period; interesting science resources in the community have been identified and briefed. The student teams have been co-driving the mobilizing of the schools and the local communities, and 
engaging in the first real-life actions through identifying possibly interesting science resources in the communities.

\section{GREEN PERIOD}

Nowadays the project is developing this period. The Green Period will create the knowledge, experience and documentation on which the project outcomes will be based; the resource creation will follow the project's 5 didactic challenges, stepwise building up capacity and resources towards the Red Period: the production and sharing of final results.

PHASE 3 will involve all partners, student teams and community collaborators in open dialogues to create a deeper understanding of open science schooling and the innovative learning principles involved in open science schooling; the dialogues will in particular focus on school collaboration with relevant science and innovation resources in the community and in the region student teams as well as community collaborators will be deeply engaged in the open dialogues and student teams are expected to share their experience with their peers from the other participating countries.

PHASE 4 will involve all partners, student teams and community collaborators in open dialogues to create an understanding of HOW open science schooling can be integrated in secondary school; the different forms of integration will be examined and debated intensely: Integrated in science subjects? Integrated in cross-subject project-based activities? Organised in open or free spaces in the (science) curricula? Student teams as well as community collaborators will be deeply engaged in the open dialogues and student teams are expected to share their experience with their peers from the other participating countries.

PHASE 5 as the project's final Guidelines will not be deducted from theoretical assumptions, but based on real and authentic student experience, the long phase 5 will engage all participating student teams in real-life science challenges and activities in their local/regional communities; this engagement is expected to create a very rich experience bank from which the project's knowledge and final outcomes can be developed and produced. The 10 student teams from the 5 participating secondary schools will engage in authentic science activities in their local or regional community; the engagement will be based on the following overall engagement design: a. identifying relevant and challenging science activities in the local/regional community, b. establishing dialogues with the selected science activities to create collaboration, c. engaging in the full circles of science or innovation activities

PHASE 6: Following the long Open Practice phase, phase 6 will engage students, teachers and collaborators in the important debate of how to document, recognize and formally assess the students' experience and capacity building The student teams will continue their transnational discussions in this phase, focusing in particular on possible differences in the participating countries' approach to documentation and formal assessment

PHASE 7: How can the students' open science schooling engagement lead to the creation of local open science schooling eco-systems?

\section{RED PERIOD}

The project's final period will transform the produced raw material, including from the Open Science Schooling Encounter, into high-quality useful outcomes. The outcome presentation will build on the project's attractive access design that was developed along the project. The final production will, of course, be accompanied by systematic and powerful local and European level sharing and dissemination.

PHASE 8 will operationalize the developed attractive access design and produce test version based on this design. The students' team will continue their transnational production, based on agreements and plans made along the Open Science Schooling Encounter Transnational: missioned to plan the final production of outcomes.

PHASE 9 will produce the final project outcomes, based on the production and elaboration of the raw material made available along the project; the project will conclude its dissemination activities along 
the project with a systematic and powerful dissemination of the final outcomes. The students' team will continue their transnational production, based on agreements and plans made along the Open Science Schooling Encounter

\section{RESULTS}

\subsection{Comparison between Open Science Schooling and some learning methods}

In the plane of the analysis of the knowledge in itself we find constructivism and constructionism, two epistemologies. The main authors of constructivism are Jean Piaget (1896-1980) and Lev Vygotsky (1896-1934) and, of the constructionism, Seymour Papert (1928-2016). The two theories question the understanding of the "reality" and the "real" as independent concepts of the observer and the idea of an objective reality independent of the person's thought. For both conceptions, knowledge consists of a psychological and social constructive process of reality and this process determines human behaviour.

The first question to ask is: how is knowledge built? Knowledge is not a physical element that can be transmitted in a direct and perfect way. The difference between constructivism and constructionism has as its essence the approach of the construction of reality. For constructivists reality is built from the individual perspective linked to their own life experiences, perceptions of the environment and mental structure. For constructionists, reality is built through an exchange between individuals who share a cultural context. The constructivists postulate a mental world and theorize about their relationship with an external world. Constructors consider that both the concepts of the mind and the world are constitutive of discursive practices. Constructivism is characterized by being focused on the person and realizes that this, based on their previous experiences and with the interaction with others, builds new knowledge [1]. On the other hand, constructionism conceives that knowledge is not a copy of reality, but a construction of human beings. Knowledge is a process that is based on the schemes that the person already presents, that is, with everything that has already been built in their relationship with the environment. Constructionism is developed primarily in the field of social and political psychology [2], being the most powerful current in social constructionism. In it, apart from the individual and the surrounding environment, there appears a third element in the construction of knowledge: language, which allows the relationship between individuals. It is in this network of social communication where a part of the knowledge remains.

If we study a more practical aspect of knowledge we find the "Learning by doing". The main author of Learning by doing is John Dewey (1859-1952) and is based on three assumptions: 1 . people learn best when they are personally involved in the learning experience; 2 . knowledge has to be discovered by the individual if it is to have any significant meaning to them or make a difference in their behaviour; and 3. a person's commitment to learning is highest when they are free to set their own learning objectives and are able to actively pursue them within a given framework [3].

John Dewey [4] defined basic concepts in My Pedagogic Creed. Below are the essential ideas: Education comes from the participation of the individual in social consciousness. Preparing the child for future life means giving him an awareness of himself and his judgment to capture the conditions under which it must be carried out. The educational process has two aspects that cannot be subordinate among them: a psychological and a sociological one. Education, therefore, must begin with a psychological vision of the child's abilities, interests and habits. Education is the fundamental method of social progress and reform is a process of life not a preparation for future life. The school is primarily a social institution. It is the community way of life in which the most effective agents are concentrated to provide the child with the inherent resources of people and to use their capacities for social purposes. School life should gradually grow out of family life. It is not a place where certain information or certain lessons will be given, where certain habits will be form. The teacher is not in school to impose certain ideas or to form particular habits in the child, but there is a member of the community to select the influences that will affect the child and help him respond adequately to these influences.

The Montessori Method defends that each child contains in their interior the potentialities of the adult person who will be in the future, so that he can fully develop his physical, emotional, intellectual and 
spiritual abilities. He must have freedom, a freedom that is achieved through self-discipline and order [5]. The way to exteriorize these potentialities is through the interaction with a prepared environment, rich in materials, infrastructure, affection and respect. In this environment, the boy and the girl have the possibility of following an individual process, guided by specialized professionals [6].

The European Commission presents the 5 main characteristics of the Open School:

1. Promotes collaboration with four interest groups: non-formal education, informal education, companies and civil society. In this way we can analyse social needs and improve educational systems. The latter should aim to capture the profiles, needs, contributions and relationships of all these school [...] related actors and elements towards a sustainable innovation ecosystem that will operate under a holistic framework of organizational learning and promotion of educational innovations [7].

2. The schools are conceived as a basic pillar of the welfare of the local community. As schools have the capacity to enrich local culture and promote responsible citizenship (including concepts of equity, gender inclusion and empowerment). Schools will thus aim to "act locally but think globally" [7].

3. Promotes critical thinking and creativity through learning based on the resolution of real life-inspired problems. It promotes associations that promote the expertise, the creation of networks, the sharing and the application of findings of scientific and technological research and that contribute projects of the real life in the classroom [7].

4. The commitment of parents is essential in the development of the projects. The Open Schooling model is based on the notion of scientific capital of student families [7].

5. Fight against the gender problem. Open School fights against the problem of gender through three mechanisms: adopting and integrating informal and formal educational experiences that intervene and revert traditional patterns of low participation. [...] Integrate awareness of gender bias in educational environments and the organizational change, commitment, politics and action to solve their representation through students and professor's programs. [...] Adopt and integrate new courses and curricula that are neutral by gender or attractive especially for women and girls [7].

With this work it is expected to be able to identify the main analogies and differences between the innovative OSS system and the already known methods discussed. And in this way have more resources to evaluate the OSS application. This study could provide very interesting theoretical and practical knowledge aimed at innovation in education.

\subsection{Application of Open Science Schooling in the forest issues}

The Practice Partner of Catalonia is located in the Region of Berguedà. It is important take into account that the region contributes with $70 \%$ of the wood from Catalonia. After one year (stages 1 through 4) of having analyzed the environment closest to the Secondary School in its region, it has been chosen the topic "The forest: exploitation and contribution to the sustainability". It is considered to be a topic that involves different stakeholders of local society: Wood sector companies (sawmills, biomass plant ...), the food sector (mushrooms, aromatic plants, honey ...), Research centres (Centre Tecnològic Forestal de Catalunya, Universitat Politècnica de Catalunya, Fundació Alicia ...), Administration (Department of Education, City Councils, Regional Council ...) ... The central theme of the Forest will be approached from two points of view very differentiated: Use of the forest as raw material on the one hand, and contribution from the forest to the sustainability of the other. This will allow structuring the activities around these two main axes, dealing with several contents.

During the actual scholar year, what will be done is to collect enough experimental information from the six Centres of different countries that will have implemented OSS. The objective is to see which are the best strategies to integrate the OSS in the curriculum and to compare the topics chosen and the results with these ones obtained in Catalonia. At the moment the educative curriculum anticipates the competencies development of the student body in different scopes. The main drawback is that most of the centres are structured in subjects. Each one has its own structure and contents to be distributed. When we talk about the OSS, we introduce the interrelation with the local environment of the community itself, the solution of real life problems ... and obviously in real life questions are not 
shared by subjects. First of all, we believe that the greatest challenges to incorporate new educational methodologies in the Secondary School consists of leaving this rigid structure of the subjects, dealing with the issues more transversally and real, and being able to adjust the relation of time and contents. It will also be another important challenge to get other sectors of society to be involved in the learning process of young people. During the course 2018-19 a pilot test will be carried out in the 6 centres of the Erasmus+ Project, and in the specific case of the Catalonia Secondary School we will be able to see first-hand how the indicated challenges can be solved. It will be possible to evaluate and compare how this pilot test has worked based on the results of the six Secondary Schools involved.

As discussed above and is shown in the Fig. 1, the two conductive threads of the OSS application to the forest are "Use of Resources" and "Sustainable Development". In the first one we focus on raw material, mainly from which hang wood and biomass -with content 1a Building Materials and content $1 \mathrm{~b}$ Fuel and Energetic Resources- and forest secondary products -with content 2 Mushrooms and Aromatic plants and content 3 Cooperative creation. In the matter of sustainability two contents are being worked on: content 4 centered in forest, water air and well-being and content 5 centered in forest biodiversity. All these topics are implemented in Secondary School subjects, for example: Technology, Experimental Sciences, Social Sciences, Mathematics, Entrepreneurial, English... 


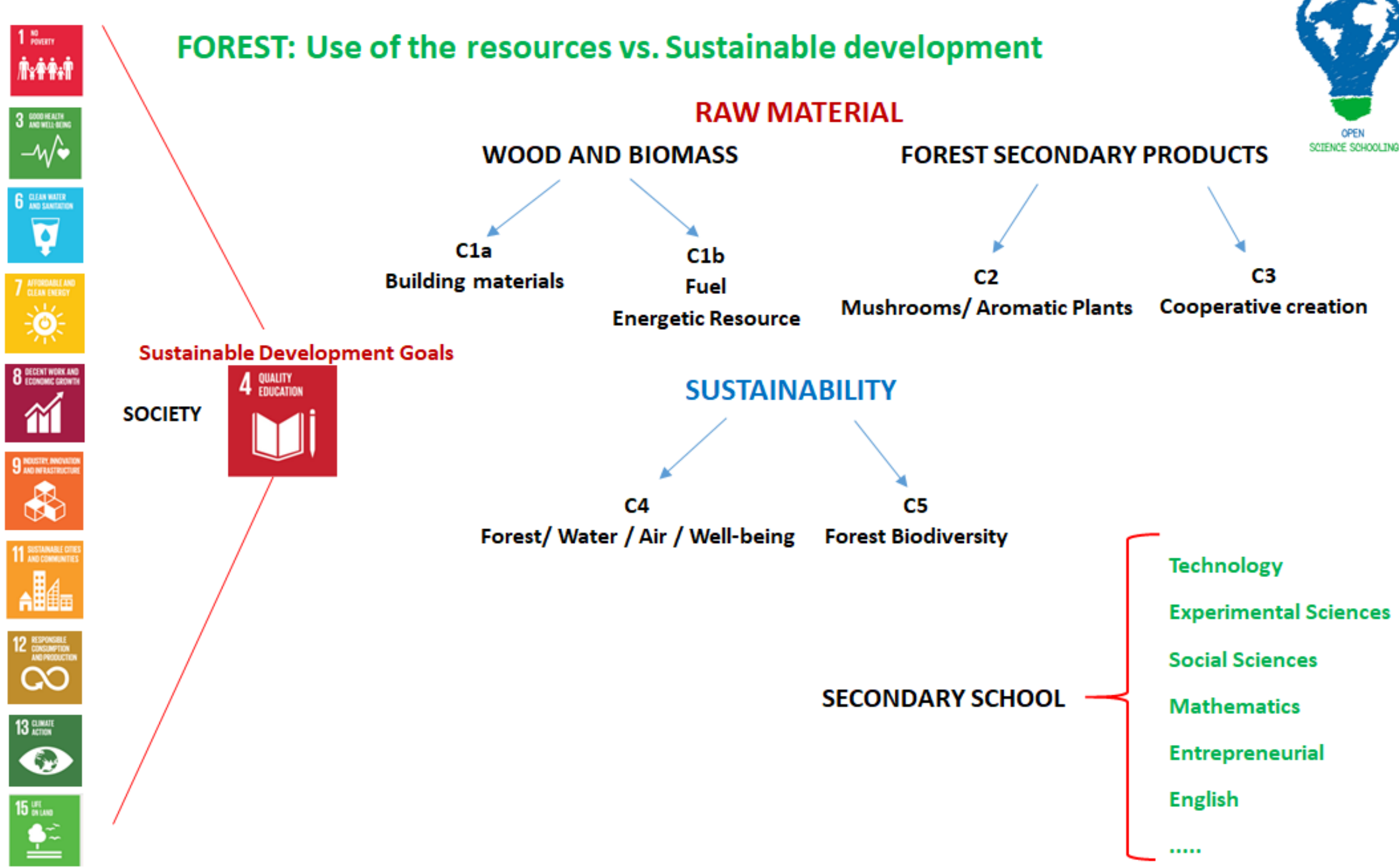

Figure 1. Diagram of application of OSS in the forest issues. 


\subsection{Activities and the relationship with the Sustainable Development Goals}

The 2030 Agenda for Sustainable Development is a plan of action for people, planet and prosperity. All countries and all stakeholders, acting in collaborative partnership, will implement this plan. The 17 Sustainable Development Goals (SDG) and 169 targets seek to realize the human rights of all and to achieve gender equality and the empowerment of all woman and girls. The 2030 Agenda is accepted by all countries and is applicable to all, taking into account different national realities, capacities and levels of development and respecting national policies and priorities. These are universal goals and targets which involve the entire world. They are integrated and indivisible and balance the three dimensions of sustainable development: the economic, social and environmental [8].

The new 2030 Agenda for Sustainable Development clearly reflects the importance of an appropriate educational response. Education is explicitly formulated as a stand-alone goal, Sustainable Development Goal 4. Education is both a goal in itself and a means for attaining all the other SDGs. It is not only an integral part of sustainable development, but also a key enabler for it. That is why education represents an essential strategy in the pursuit of the SDGs [9]. In Catalonia has been published the English to Catalan translation of "Education for Sustainable Development Goals: learning objectives" by UNESCOCAT in its role of disseminating and promoting the programs and projects of UNESCO in Catalonia.

Another objective of this work consists on finding the relationship between the activities proposed and the Sustainable Development Goals. Of the 17 SDG, Fig. 2, in this study, Goals 1, 3, 4, 6, 7, 8, 9, 11, 1213 and 15 are worked around a central objective, the Goal 4 Quality Education. All these SDG are indicated by a (*).

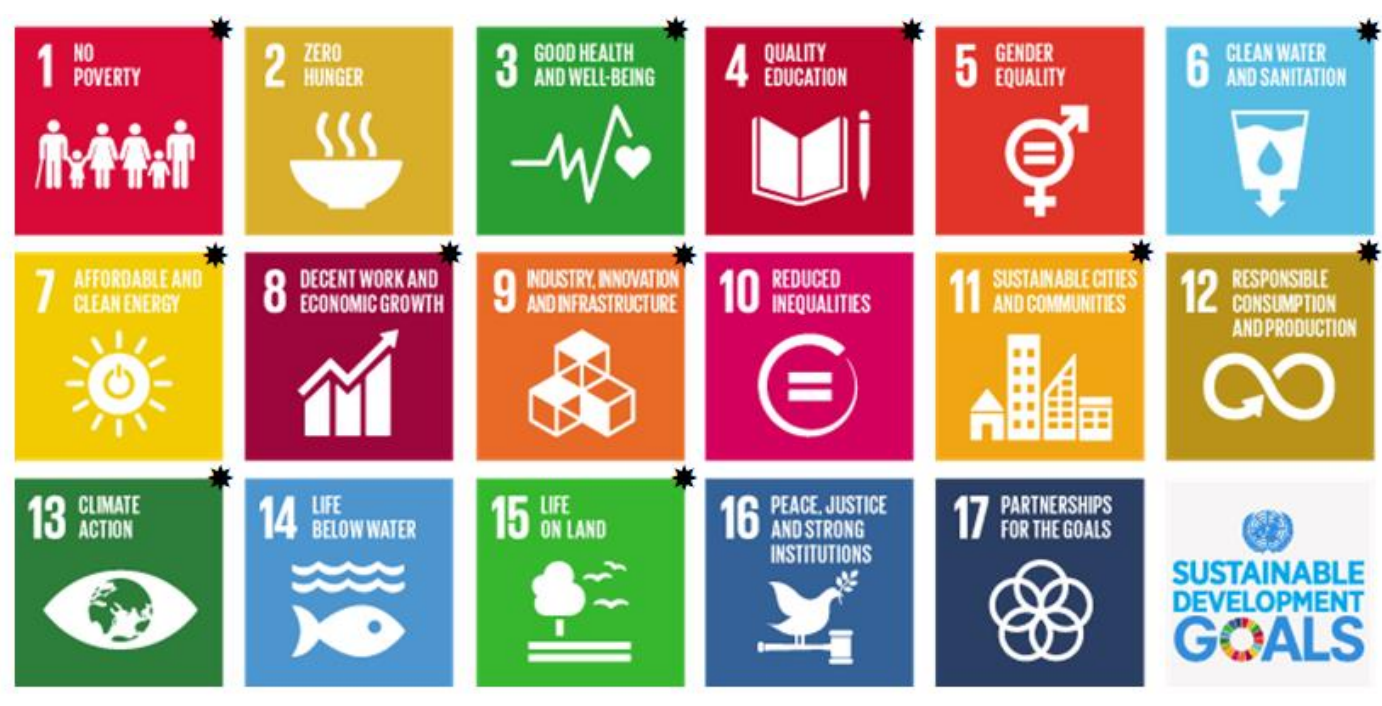

Figure 2. Sustainable Development Goals

In the Fig. 3 is shown the relationship between the forest issues, the contents explained above and the SDG corresponding to each one. This figure has been designed based on the work of [10] in which a series of actions are presented to contribute to some of the SDG. 
1. Forest situation in Catalonia

2. The forest as a raw material

Wood and Biomass

-Building materials

-Fuel, Energetic Resources

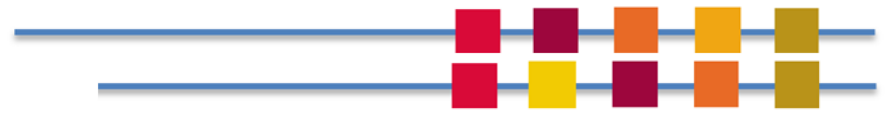

Forest secondary products

-Mushrooms / Aromatic Plants

-Cooperative creation

3. The forest and the sustainability

Forest / Water / Air / Well-being

Forest Biodiversity

Figure 3. Relationship between forest issues and SDG

\section{CONCLUSIONS}

After the comparative study, it can be stated that Open Science Schooling is a broader concept than the four methodologies outlined. Even it could be said that encompasses some theoretical and practical views of these. OSS focuses on the participation of the various sectors of society that make up the student's environment in the activities developed and in development. These elements are called stakeholders. We can relate this approach with the participation of the individual in social consciousness, a starting point for John Dewey when he defines the education. In fact, the essential ideas of his thinking with "Learning by doing" are reflected in the practice of OSS and in the proposed activities. In the same way, the environment for the development of each student defined by Montessori can be reconciled, as well the role of teaching staff as a guide in personal development and not just a knowledge transmitter.

It is important to emphasize that OSS presents a "new" really important point: the fight against the gender problem. At least one intention is drawn in developing a theoretical-practical vision for the confrontation of this social problem. Again we can perceive the conception of education as an instrument to promote social changes.

The design of activities around the Forest and based on the fulfillment of SDG is linked to the Education for Sustainable Development (EDS). This can contribute to achieving the SDGs by, first, developing cross-cutting sustainability competencies that are needed to deal with many different sustainability challenges and to relate the different SDGs to each other. Second, ESD can equip learners with the specific cognitive, socio-emotional and behavioral learning outcomes that enable them to deal with the particular challenges of each SDG [9]. It should be noted that the activities plan is in development nowadays so there are some exercises done and other in process or programmed for the following months. 


\section{REFERENCES}

[1] Parica Ramos, A. T., Bruno Liendo, F. J. and Abancin Ospina, R.A. (2005). Teoría del constructivismo social de Lev Vygotsky y comparación con la teoría Jean Piaget. Available at: http://constructivismos. blogspot.com/.

[2] Munné, F. (1999). Constructivismo, construccionismo y complejidad: la debilidad de la crítica en la psicología construccional. Psicología Social, 2-3 (14), pp. 131-144.

[3] Smith, M. K. (1980) Creators Not Consumers: Rediscovering social education, Leicester: National Association of Youth Clubs

[4] Dewey, J. (1897). My pedagogic creed, School Journal vol. 54 (January 1897), pp. 77-80

[5] Standing, M. (1985) La revolución Montessori en la educación. México: Siglo XXI Editores.

[6] Montessori, M. (1940) La formación del hombre. México: Editorial Diana

[7] Sotiriou, S., Cherouvis S. Open Schooling Model. 30 July 2017, Ref. Ares (2017) 3819918, available at: https://www.openschools.eu/open-school-model/

[8] UNESCO, Transforming our world: the 2030 Agenda for Sustainable Development, 21 October A/RES/70/1, available

at: https://sustainabledevelopment.un.org/post2015/transformingourworld.html

[9] UNESCO, Education for Sustainable Development Goals: learning objectives, 2017, ED/446, available at: https://unesdoc.unesco.org/ark:/48223/pf0000247444

[10] The Nature Conservancy, The Science of Sustainability, available at: https://www.nature.org/enus/ 